Ärztliche Erfahrung beschränkt sich nicht auf medizinisches Fachwissen. Sie entsteht auch aus den mehr oder minder alltäglichen, heiter, ärgerlich oder nachdenklich stimmenden Erlebnissen mit Patienten, Kollegen und Mitarbeitern. Senden Sie uns Ihre Geschichte an: Brigitte.Moreano@springer.com. Für jeden veröffentlichten Text erhalten Sie bis zu 100 Euro.

\title{
Feinheiten der Sprache
}

- In der allgemeinmedizinischen Sprechstunde stellt sich öfters heraus, dass Symptome eher durch eine psychische Belastung hervorgerufen werden. Gerade Frauen kommen oft schon direkt damit an und haben häufig eine konkrete Vorstellung, womit welches Problem zusammenhängt.

So auch sie, noch keine 50, eher jünger wirkend, vital, schaffensfroh und zupackend. Die Kinder sind (gerade) aus dem Haus, sie hat sich einen Job gesucht, der sie ausfüllt und in dem sie schon viel Veränderung ins Team eingebracht hat. Dafür sind ihr alle ganz dankbar, sodass sie dort viel Bestätigung bekommt. Sie macht die Dinge gern zu Ende, bevor sie sich ausruht, auch, wenn es über ihren Feierabend hinausgeht. Nebenbei ist sie kirchlich sehr engagiert

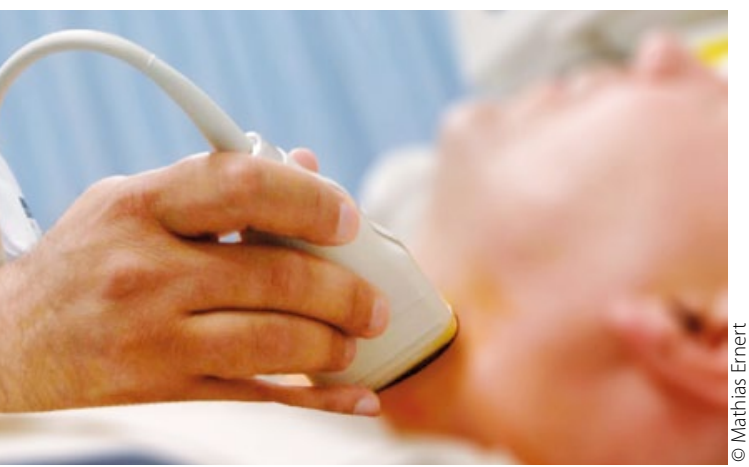

Beim Hausarzt: Check-up zum kleinen Preis.

— Als Ärztin einer Kleinstadt schaue ich öfter fassungslos auf das, was sich in den Großstädten unseres Landes tut. So auch neulich bei einem Fernsehbeitrag, der sich um die Gesundheits-Checks der Leute mit und unterhält ein offenes, gastliches Haus für ihre Kinder und Freunde. Sie kann nicht wegsehen, wenn jemand Hilfe braucht, sondern packt zu. Sie nimmt normalerweise auch kein Blatt vor den Mund, wenn sich jemand danebenbenimmt. Wenn ich sie so sehe und höre, habe ich Respekt vor dem, was sie leistet und staune, wo sie die Energie dafür hernimmt.

Sie hat Magenschmerzen. Sie beschwert sich, dass ihr Mann nervt. Er meint, sie verausgabe sich zu sehr. Sie versuche, das als "liebevolle Fürsorge" einzuordnen, fühle sich aber in Wirklichkeit eher bevormundet und ärgere sich. Sie schlucke das meist runter, wolle sich nicht andauernd mit ihm streiten, habe Angst, er könne sie dann verlassen.
Um sie zu einem weiteren Perspektivwechsel anzuregen, werfe ich die Frage ein, ob sie mit ihrem "Gutmensch-Verhalten" nicht "die Norm verdirbt", sodass ihr Mann sich neben ihr zu klein vorkommt. Schweigen. Ob das bei ihr ankommt? Schwer zu sagen. Da meint sie zum Abschied, sie habe ein selbstgebackenes Brot mitgebracht und ich könne mir davon gerne eine Scheibe abschneiden.

Als ich mich bedanke und noch einmal wiederhole, dass ich mir davon gern eine Scheibe abschneiden werde, macht es bei ihr Klick. Sie lacht und bedankt sich. Nun bin ich mal gespannt, wie es bei ihr und mit ihrem Mann weitergehen wird.

Dr. Med. ANdREA LinSEL, LÜNEBURG =

\section{Sinnlose Vorsorge}

überflüssigem Geld drehte: $3000 €$ kostete die Überprüfung, die sich nur über eine gute Stunde erstreckte (in dieser Zeit wurden 15 verschiedene Untersuchungen gemacht, teilweise so banal wie Ergometrie und Lungenfunktionstest) plus ein MRTGanzkörperscan.

Bei der Doppleruntersuchung der Karotiden fragte ich mich, ob die notwendigen zwölf Messpunkte für eine genaue Bestimmung der Intima-Media-Dicke wohl aufgesucht wurden; angesichts der knappen Zeit bezweifelte ich dies.

Gefragt, was den hohen Preis rechtfertige, meinte der Arzt (natürlich mit Professorentitel): „Man bekommt ohne Zeitverzö- gerung alle Untersuchungen hintereinander". Leider wurde er nicht gefragt, ob er den Patienten rate, den Check nun halbjährlich durchführen zu lassen, um sich jederzeit seiner Gesundheit sicher zu sein. Die Patienten dieser Privatklinik waren alle wohlhabend, oft jung und gebildet. Seltsam, dass sie gar nicht gemerkt haben, wie sinnlos sie ihr Geld zum Fenster hinausgeworfen haben! Die sinnvollen Untersuchungen würde ihr Hausinternist gern zügig, kompetent und zu einem Bruchteil des Preises durchführen (das gesparte Geld könnte man dann z. B. einer Obdachlosenklinik spenden). Aber das wäre ja nicht „stylish“.

DR. MED FranKE hÖlLERING, ARNSBERG . 